OPEN ACCESS

Edited by:

Dario Coletti,

Sapienza University of Rome, Italy

Reviewed by:

John Joseph McCarthy, University of Kentucky, United States

Bianca Maria Scicchitano,

Catholic University of the Sacred

Heart, Italy

*Correspondence:

Chiara Mozzetta

chiara.mozzetta@uniroma1.it

Luca Madaro

I.madaro@hsantalucia.it

Specialty section:

This article was submitted to

Striated Muscle Physiology,

a section of the journal

Frontiers in Physiology

Received: 01 April 2019

Accepted: 05 August 2019

Published: 21 August 2019

Citation:

Biferali B, Proietti D, Mozzetta C and Madaro L (2019)

Fibro-Adipogenic Progenitors Cross-Talk in Skeletal Muscle:

The Social Network.

Front. Physiol. 10:1074.

doi: 10.3389/fphys.2019.01074

\section{Fibro-Adipogenic Progenitors Cross-Talk in Skeletal Muscle: The Social Network}

\author{
Beatrice Biferali1,2, Daisy Proietti3,4, Chiara Mozzetta ${ }^{2 *}$ and Luca Madaro ${ }^{3 *}$ \\ ${ }^{1}$ Department of Biology and Biotechnology "C. Darwin," Sapienza University of Rome, Rome, Italy, ${ }^{2}$ Institute of Molecular \\ Biology and Pathology (IBPM), CNR National Research Council of Italy, c/o Department of Biology and Biotechnology "C. \\ Darwin," Sapienza University of Rome, Rome, Italy, ${ }^{3}$ IRCCS Santa Lucia Foundation, Rome, Italy, ${ }^{4}$ DAHFMO-Unit of \\ Histology and Medical Embryology, Sapienza University of Rome, Rome, Italy
}

Skeletal muscle is composed of a large and heterogeneous assortment of cell populations that interact with each other to maintain muscle homeostasis and orchestrate regeneration. Although satellite cells (SCs) - which are muscle stem cells - are the protagonists of functional muscle repair following damage, several other cells such as inflammatory, vascular, and mesenchymal cells coordinate muscle regeneration in a finely tuned process. Fibro-adipogenic progenitors (FAPs) are a muscle interstitial mesenchymal cell population, which supports SCs differentiation during tissue regeneration. During the first days following muscle injury FAPs undergo massive expansion, which is followed by their macrophage-mediated clearance and the reestablishment of their steady-state pool. It is during this critical time window that FAPs, together with the other cellular components of the muscle stem cell niche, establish a dynamic network of interactions that culminate in muscle repair. A number of different molecules have been recently identified as important mediators of this cross-talk, and its alteration has been associated with different muscle pathologies. In this review, we will focus on the soluble factors that regulate FAPs activity, highlighting their roles in orchestrating the inter-cellular interactions between FAPs and the other cell populations that participate in muscle regeneration.

Keywords: FAPs, fibrosis, cytokine - immunological terms, muscle regeneration, stem cell

\section{INTRODUCTION}

Skeletal muscle is the most abundant tissue in healthy humans, accounting for $40 \%$ of body weight. It is composed of multinucleated contractile cells called myofibers, which are formed during development by fusion of differentiated mononuclear muscle cells, and their number remains constant during post-natal growth. The regenerative potential of skeletal muscle relies primarily on satellite cells (SCs), the prototypical muscle stem cells. Upon muscle injury SCs enter the cell cycle, proliferate, and differentiate to repair damaged myofibers, while self-renewing to repopulate the reserve pool (Feige et al., 2018).

Recently, several studies have indicated that the establishment of functional cross-talk between SCs and other cell types within the muscle niche, including motor neurons, endothelial cells, immune cells, fibrogenic cells, and adipogenic precursors, is crucial for muscle repair and homeostasis (Tatsumi et al., 2009; Joe et al., 2010; Uezumi et al., 2010; Heredia et al., 2013; 
Saccone et al., 2014; Kuswanto et al., 2016; Verma et al., 2018; Giordani et al., 2019; Lukjanenko et al., 2019). Indeed, different stem/progenitor cell types are recruited to the regenerative niche and influence muscle regeneration either by directly differentiating into muscle cells or by releasing paracrine factors (i.e., growth factors, cytokines) that control the regenerative response of SCs (Pannérec et al., 2012). Among the noncellular components of the SCs niche the extra-cellular matrix (ECM) plays a crucial role by undergoing a transient remodeling during acute injury, followed by a prompt termination to avoid pathological fibrosis and tissue degeneration. Although recent findings have shown that myogenic cells can produce ECM components (Fry et al., 2017b; González et al., 2017; Baghdadi et al., 2018), and a recently identified population of interstitial tenocytes has been implicated in ECM deposition in vivo (Giordani et al., 2019), the main cellular sources of ECM proteins are fibroblasts, myo-fibroblast, and fibro-adipogenic progenitors (FAPs) (Serrano and Muñoz-Cánoves, 2010; Lemos et al., 2015; Contreras et al., 2016; Mueller et al., 2016).

Since their discovery FAPs have attracted a considerable attention (Joe et al., 2010; Uezumi et al., 2010), in particular, their phenotypical plasticity, which appears critical for efficient muscle repair. FAPs have been defined as multi-potent progenitors, having the ability to differentiate into fibroblasts, adipocytes, and possibly into osteoblasts and chondrocytes, although not into myoblasts (Joe et al., 2010; Uezumi et al., 2010). They share the expression of cell surface markers, such as Sca-1 and PDGFR $\alpha$ with mesenchymal stem cells and can therefore be broadly defined as mesenchymal precursors (Joe et al., 2010; Mueller et al., 2016; Judson et al., 2017; Malecova et al., 2018; Giordani et al., 2019).

Under quiescent conditions FAPs frequently localize close to blood vessels but unlike pericytes FAPs reside outside the capillary basement membrane and do not express NG2 (Joe et al., 2010).

However, upon muscle injury, FAPs become activated, proliferate and expand, and provide a transient favorable environment to promote SCs-mediated regeneration (Joe et al., 2010; Heredia et al., 2013; Mozzetta et al., 2013). FAPs expansion is critical during regeneration in order to sustain SCs differentiation in a paracrine manner and to maintain the SCs pool (Wosczyna et al., 2019). Indeed, in vivo depletion of FAPs clearly established their absolute requirement for regeneration and long-term maintenance of skeletal muscle (Wosczyna et al., 2019). However, as regeneration proceeds, FAPs are cleared from the regenerative niche by apoptosis (Lemos et al., 2015) and failure in doing so has been associated with their pathological accumulation and with a number of muscle dysfunctions. In fact, beyond their supportive role in muscle regeneration, FAPs have been identified as the major source of infiltrating fibroblasts and adipocytes in degenerating dystrophic muscles (Uezumi et al., 2010, 2011; Mozzetta et al., 2013; Kopinke et al., 2017). Similarly, in chronic atrophic conditions, caused by moto-neurons deficits, increased fibrosis is associated with accumulation of FAPs in the interstitium of denervated muscles (Contreras et al., 2016; Fry et al., 2017a; Madaro et al., 2018; Rebolledo et al., 2019). Likewise, intra-muscular fatty infiltration and obesity-associated muscle dysfunctions have been also linked to FAPs accumulation and fibro-adipogenic differentiation (Dammone et al., 2018; Gorski et al., 2018; Kang et al., 2018; Pagano et al., 2018; Buras et al., 2019).

These findings emphasize that the FAPs lineage decisions are dramatically influenced by signals released in their microenvironment, whose pathological alteration might culminate in excessive ECM accumulation (Lemos et al., 2015; Contreras et al., 2016; Dammone et al., 2018; Madaro et al., 2018), acquisition of altered cell fates, as in the case of heterotypic ossification (Lees-Shepard et al., 2018), and impaired myogenesis. In physiological conditions, FAPs' crosstalk with other cell populations is emerging as an important and finely orchestrated process crucial for a successful muscle regeneration. While it is now well established that a cross-talk between SCs and fibrogenic cells is necessary for efficient SCs expansion in response to injury, and to prevent interstitial fibrosis accumulation (Murphy et al., 2011; Fry et al., 2017b; Lukjanenko et al., 2019), increasing evidence indicates that FAPs also actively interact with immune cells in a finely tuned manner (Heredia et al., 2013; Lemos et al., 2015; Malecova et al., 2018; Moratal et al., 2018).

Taken together, these observations demonstrate that FAPs orchestrate a plethora of processes involved in regenerative myogenesis, which have been recently reviewed elsewhere (Wosczyna and Rando, 2018). In this mini-review, we will instead specifically focus on the secreted signals, cytokines, and paracrine factors controlling FAPs function and those released by FAPs monitoring the different cell types involved in muscle repair. We will first describe the signals secreted by the various cell populations present in the regenerative niche known to directly influence FAPs activity and then discuss the signals released by FAPs themselves, highlighting their cellular targets and functions (Table 1).

\section{THE SECRETOME THAT REGULATES FAPS ACTIVITIES}

\section{IL-4 and IL-13 Family}

Interleukin-4 (IL-4) and IL-13 are Th2 cytokines, which have been implicated as mediators in the cross-talk between the immune system and FAPs (Heredia et al., 2013). The innate immune system is activated rapidly upon muscle injury and triggers the recruitment of Th2 lymphocytes, macrophages, mast cells, and eosinophils to the injured sites (Tidball and Villalta, 2010; Heredia et al., 2013).

Interleukin-4/IL-13 signaling is crucial for skeletal muscle repair, as demonstrated by studies showing a complete absence of regenerated myofibers, persistence of cellular debris, and an inflammatory infiltrate, in the muscles of $I L-4 / I L-13^{-/-}$ mice following cardiotoxin-induced injury (Heredia et al., 2013). Although activation of type 2 immune responses has been classically associated with alternatively activated (M2) macrophages (Allen and Wynn, 2011; Palm et al., 2012), eosinophils have been recently identified as the dominant cell source of IL-4 and IL-13 (Heredia et al., 2013) during 
TABLE 1 | Schematic table illustrating the principal molecules, the producing and target cells, and the corresponding biological effects, that have been shown to act on, or be released by, FAPs.

FAPs social network

\begin{tabular}{|c|c|c|c|c|c|}
\hline \multicolumn{6}{|c|}{ FAPs social network } \\
\hline Molecule & $\begin{array}{l}\text { Production } \\
\text { cells }\end{array}$ & Target & Effects & References & $\begin{array}{l}\text { Experimental } \\
\text { conditions }\end{array}$ \\
\hline TGF- $\beta$ & Macrophages & FAPs & $\begin{array}{l}\text { TGF- } \beta \text { induces FAPs fibrogenic differentiation and blocks } \\
\text { TNF-induced FAPs apoptosis. }\end{array}$ & $\begin{array}{l}\text { Uezumi et al., 2011; Lemos } \\
\text { et al., 2015; Davies et al., } \\
2016\end{array}$ & In vitro and in vivo \\
\hline$\| \mathrm{L}-15$ & $\begin{array}{l}\text { Muscle } \\
\text { fibers }\end{array}$ & FAPs & $\begin{array}{l}\mathrm{IL}-15 \text { stimulates FAPs proliferation and prevents adipogenic } \\
\text { differentiation in vitro and in vivo and promotes } \\
\text { FAPS-induced SC differentiation. }\end{array}$ & Kang et al., 2018 & In vitro and in vivo \\
\hline $\mathrm{IL}-4$ & Eosinophils & FAPs & $\begin{array}{l}\text { IL-4 inhibits adipogenic differentiation of FAPs and } \\
\text { increases FAPs ability to remove cellular debris enhancing } \\
\text { regeneration. }\end{array}$ & $\begin{array}{l}\text { Heredia et al., 2013; Dong } \\
\text { et al., } 2014\end{array}$ & In vitro and in vivo \\
\hline$\| \mathrm{L}-13$ & & FAPs & $\begin{array}{l}\text { IL-13 promotes FAPs proliferation that supports } \\
\text { myogenesis, while inhibits FAPs differentiation into } \\
\text { adipocytes. }\end{array}$ & Heredia et al., 2013 & In vitro and in vivo \\
\hline TNF- $\alpha$ & Macrophages & FAPs & $\begin{array}{l}\text { TNF- } \alpha \text { induces FAPs apoptosis preventing excessive } \\
\text { deposition of extracellular matrix during regeneration. }\end{array}$ & Lemos et al., 2015 & In vitro and in vivo \\
\hline \multirow[t]{2}{*}{ IL-6 } & FAPs & Myotubes & IL-6 promotes myogenic differentiation. & Joe et al., 2010 & In vitro \\
\hline & & FAPs & $\begin{array}{l}\text { IL-6 promotes pro-atrophic FAPs phenotype during } \\
\text { denervation. }\end{array}$ & Madaro et al., 2018 & In vitro and in vivo \\
\hline IL-33 & FAPs & $\begin{array}{l}\text { Regulatory } \\
\text { T cells }\end{array}$ & $\begin{array}{l}\text { IL-33 increases Treg cells proliferation promoting muscle } \\
\text { repair. }\end{array}$ & Kuswanto et al., 2016 & In vitro and in vivo \\
\hline Follistatin & FAPs & $\begin{array}{l}\text { Satellite } \\
\text { cells }\end{array}$ & $\begin{array}{l}\text { FAPs-secreted follistatin promotes multinucleated } \\
\text { myotubes formation. }\end{array}$ & Mozzetta et al., 2013 & In vitro \\
\hline IL-10 & FAPs & Myotubes & $\begin{array}{l}\mathrm{IL}-10 \text { is upregulated in FAPs during muscle regeneration. Its } \\
\text { role is still unknown but the hypothesis is that the secretion } \\
\text { of IL-10 facilitates myoblast differentiation by preventing the } \\
\text { antimyogenic activity of TNF and IL-1 } 1 \beta \text {. }\end{array}$ & Lemos et al., 2012 & $\mathrm{n} / \mathrm{a}$ \\
\hline $\begin{array}{l}\text { BMP1- } \\
\text { MMP14 }\end{array}$ & FAPs & Macrophages & $\begin{array}{l}\text { FAPs-secreted BMP1 and MMP14 activate TGF- } \beta \\
\text { produced by macrophages in fibrotic DMD muscle. }\end{array}$ & Juban et al., 2018 & In vitro \\
\hline WISP1 & FAPs & $\begin{array}{l}\text { Satellite } \\
\text { cells }\end{array}$ & $\begin{array}{l}\text { FAPS-secreted WISP1 regulates satellite cell expansion and } \\
\text { asymmetric differentiation. FAPS-derived WISP1 is lost } \\
\text { during aging impairing muscle regeneration. }\end{array}$ & Lukjanenko et al., 2019 & In vitro and in vivo \\
\hline
\end{tabular}

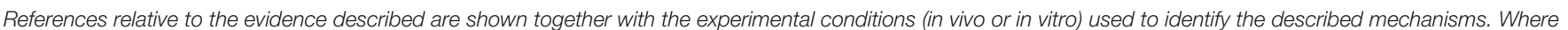
experimental evidence is lacking we indicated the experimental procedure with n/a.

skeletal muscle regeneration. Specifically, it has been shown that eosinophils secrete IL-4 to activate the regenerative actions of FAPs. Indeed, Heredia et al. (2013) identified FAPs as the cells specifically expressing the IL- $4 \mathrm{R} \alpha$, demonstrating, both in vitro and in vivo, that FAPs are the cellular targets of IL-4/IL-13 signaling during muscle regeneration. Intriguingly, they also unveiled a previously unrecognized function of FAPs: their capacity to phagocytoze necrotic debris, a crucial process for successful completion of muscle repair (Heredia et al., 2013). In addition, IL-4/IL-13 signaling, via activation of STAT6, promotes FAPs proliferation to support myogenesis, while inhibiting their differentiation into adipocytes (Heredia et al., 2013). Accordingly, in the injured muscles of IL-4-knockout mice, the levels of adipocytes are increased, while in vitro and in vivo administration of IL-4 inhibits FAPs adipogenesis (Heredia et al., 2013; Dong et al., 2014). In agreement with these observations, glucocorticoids (GCs)-induced repression of IL-4 leads to intramuscular adipogenic accumulation by promoting FAPs proliferation and differentiation into adipocytes (Dong et al., 2014). Since GCs are known to suppress eosinophils, it is likely that they inhibit IL-4 signaling by reducing the number of infiltrating eosinophils upon muscle injury (Dong et al., 2014). Yet, IL-4-polarized, anti-inflammatory macrophages have been shown to induce adipogenesis of human FAPs isolated from dystrophic muscles (Moratal et al., 2018), suggesting that IL-4 signaling might govern more complex cellular interactions than previously expected.

\section{IL-15}

Interleukin-15 is expressed in human skeletal muscle and it has been identified as an anabolic factor involved in muscle growth (Quinn et al., 2002; Furmanczyk and Quinn, 2003). Indeed, IL-15 can decrease protein degradation in muscle (Busquets et al., 2005) and modulate muscle-adipose tissues interactions (Quinn et al., 2005). A recent work identified IL-15 as a myokine able to prevent intramuscular fatty infiltration, likely affecting FAPs differentiation capacities (Kang et al., 2018). In this work, the authors showed that IL-15 stimulates FAPs proliferation and it directly inhibits their adipogenic differentiation, both in vitro and in vivo, ultimately facilitating myofibers regeneration (Kang et al., 2018). Moreover, intramuscular administration of a recombinant IL-15 prevented fat accumulation in the murine 
model of glycerol-induced fatty degeneration (Kang et al., 2018). Accordingly, in vitro treatment of FAPs with IL-15 impaired their capacity to differentiate into adipocytes (Kang et al., 2018), likely through the induction of desert Hedgehog (DHH) signaling, a known repressor of FAPs adipogenesis (Kopinke et al., 2017). Although these results suggest a positive role for IL-15 in muscle regeneration, the evidence that IL-15 administration, and expression, correlates with increased collagen deposition in vivo after muscle damage (Kang et al., 2018), poses several unresolved issues that warrant further investigation. Indeed, whether IL15 directly promotes FAPs differentiation into fibroblasts has not been tested yet. Furthermore, even though FAPs expansion and regenerative fibrogenesis have a positive impact on acute muscle regeneration (Heredia et al., 2013; Fiore et al., 2016), the evidence that IL-15 expression is positively correlated with the number of FAPs and collagen deposition in subjects with rotator cuff tear indicates that IL-15 might serve, instead, as a signal to sustain FAPs pathogenic fibrogenesis in chronically fibrotic muscles.

\section{TNF- $\alpha$}

Tumor necrosis factor-alpha (TNF- $\alpha$ ) is a pleiotropic cytokine secreted rapidly upon muscle damage by infiltrating inflammatory cells and its impact on muscle regeneration is still under debate. Indeed, while pharmacological blockade of TNF- $\alpha$ has been associated with reduced muscle necrosis and amelioration of the histological profile of dystrophic muscles (Hodgetts et al., 2006; Huang et al., 2009; Piers et al., 2011; Ermolova et al., 2014). More recently, TNF- $\alpha$ has been implicated in preventing FAPs aberrant accumulation (Lemos et al., 2015; Fiore et al., 2016), suggesting that anti-TNF therapies might instead exert a pro-fibrotic effect.

During acute injury, TNF- $\alpha$ has been reported to promote muscle repair by activating promyogenic $\mathrm{p} 38$ signaling (Chen et al., 2007), thus inducing SCs differentiation (Palacios et al., 2010). Recently, it has been suggested that TNF- $\alpha$ regulates matrix production during acute damage, thus unveiling a crucial function for TNF- $\alpha$ in mediating FAPs apoptosis and clearance (Lemos et al., 2015; Fiore et al., 2016). Specifically, TNF$\alpha$ was found to be predominantly expressed and produced by infiltrating monocytes that rapidly differentiate into proinflammatory macrophages (M1) that accumulate in close proximity to expanding FAPs. By using a mouse model unable to recruit circulating monocytes to damaged muscles [the CC chemokine receptor type $2(\mathrm{Ccr} 2)^{-/-}$mouse strain (Warren et al., 2005)], Lemos et al. (2015) elegantly demonstrated that in the absence of infiltrating TNF-a-producing macrophages, FAPs accumulate in the sites of damage and aberrantly differentiate into fibrogenic cells. Inflammatory cell-derived TNF- $\alpha$ production is therefore required for FAPs clearance to prevent pathological ECM accumulation. Of note, this physiological role is altered in chronically damaged muscles, such as those of dystrophic mice, where the abundance of transforming growth factor beta 1 (TGF- $\beta 1$ ) signaling impairs the pro-apoptotic effects of TNF- $\alpha$ on FAPs (Lemos et al., 2015). These data might offer a possible explanation for the apparent controversial results reporting a positive effect of anti-TNF- $\alpha$ therapies on dystrophic mice (Hodgetts et al., 2006; Huang et al., 2009; Piers et al., 2011; Ermolova et al., 2014). Indeed, when TGF- $\beta 1$ is abundant, as in chronic degenerating muscles, the anti-fibrotic role of TNF- $\alpha$ is irrelevant and pharmacological approaches aimed at inhibiting its activity most likely exert their beneficial effects through targeting of the pro-myogenic, SC-mediated function of TNF- $\alpha$.

\section{TGF- $\beta$}

The transforming growth factor beta (TGF- $\beta$ ) superfamily comprises pleiotropic and multifunctional secreted peptides implicated in a wide range of cell functions, including tissue homeostasis and repair, immune and inflammatory responses, ECM deposition, cell differentiation, and growth (Biernacka et al., 2011; Meng et al., 2016). Studies in a wide range of experimental models have firmly established TGF- $\beta 1$ as a crucial mediator of fibrinogenesis and inhibition of its activity has consistently been associated with reduced fibrosis (Biernacka et al., 2011; Meng et al., 2016).

In the context of skeletal muscle, inhibition of TGF- $\beta 1$ has been linked to improvement in muscle regeneration and decreased fibrosis (Davies et al., 2016; Song et al., 2017; Zhang et al., 2019), consistent with the importance of the TGF- $\beta 1$ signaling in regulating both regeneration and matrix production. Several works have elucidated the detrimental, cell-autonomous, impact of TGF- $\beta$ signaling on muscle stem cells by inhibiting their activation (Carlson et al., 2008; Wang et al., 2016) and terminal differentiation (Carlson et al., 2008) while promoting a fibrogenic switch in chronically degenerating muscles (Biressi et al., 2014).

Nonetheless, recent findings point toward a prominent role for inflammatory cell-derived TGF- $\beta$ signaling in the survival and fibrotic differentiation of FAPs. Specifically, during chronic muscle damage, macrophages express and secrete high levels of TGF- $\beta 1$, antagonizing the TNF-mediated apoptosis of FAPs, and instead induce their fibrogenic differentiation and consequent ECM deposition (Lemos et al., 2015; Davies et al., 2016; Fiore et al., 2016; Juban et al., 2018). Thus, in conditions of chronic muscle damage, TGF- $\beta 1$ acts as a dominant, prosurvival signal that overrides the beneficial effect of the proinflammatory cell-derived, and anti-fibrotic cytokine, TNF- $\alpha$. Thus, treatment with nilotinib, via specific inhibition of TGF$\beta 1$-induced p38 signaling, restores FAPs apoptosis and prevents fibrotic accumulation in dystrophic mice (Lemos et al., 2015).

Of note, FAPs from chronic fibrotic dystrophic muscles have been identified as the main source of TGF- $\beta$-activating enzymes (Juban et al., 2018). Indeed, once released, latent TGF- $\beta 1$ must be activated, either via enzymatic or mechanical mechanisms, to exert its properties and to bind to its receptors (Travis and Sheppard, 2014). FAPs exhibit high expression of a series of latent TGF- $\beta 1$ activators, among which matrix metallo proteinase 14 (MMP14) and bone morphogenetic protein 1 (BMP1) are able to activate the latent TGF- $\beta 1$ released by pro-inflammatory macrophages (Juban et al., 2018). Notably, pharmacological inhibition of BMP1 or MMP14 reduced muscle fibrosis in dystrophic mice resulting in increased muscle fiber size and reduced necrosis (Juban et al., 2018). 
In summary, these data support a model through which chronic inflammation and fibrosis reciprocally sustain themselves in degenerating dystrophic muscles, by reinforcing a regulatory cross-talk between inflammatory cells and FAPs.

\section{MOLECULES SECRETED BY FAPS}

\section{IL-6}

In skeletal muscle, IL-6 is classified as a myokine produced and released by muscle fibers in response to contraction (Pedersen and Febbraio, 2008). It promotes lipolytic and anti-inflammatory beneficial effects during exercise (Pedersen et al., 2003), working as an energy sensor and exerting both local and endocrine metabolic effects.

Interleukin-6 regulates both muscle hypertrophy and regeneration (Muñoz-Cánoves et al., 2013). Indeed, IL-6 knockout mice show a reduced hypertrophic response to overloading, ascribed to impaired myonuclei incorporation as a consequence of the defective proliferation and migration of SCs. Treatment with IL-6 promotes murine SCs proliferation, via regulation of cell-cycle associated genes, Cyclin D1 and c-Myc (Serrano et al., 2008), while during regeneration the IL-6/STAT3 axis controls SCs fate (Tierney et al., 2014). Interestingly, FAPs were identified as one of the main source of IL- 6 during muscle regeneration. Upon muscle injury, IL-6 expression remains constant in myogenic progenitors but increases nearly 10-fold in FAPs and in vitro co-culture experiments have shown that IL-6 mediates the pro-myogenic activity of FAPs (Joe et al., 2010).

The positive effect of IL-6, and others myokines, is normally associated with transient production and short-term action. By contrast, persistent inflammatory conditions, denervation, and some types of cancer and other chronic diseases have been associated with long-lasting elevated IL-6 levels. In agreement with this notion, IL-6 has been shown to promote skeletal muscle atrophy (Haddad et al., 2005). Accordingly, in denervated muscles, FAPs show a persistent activation of IL-6, thus promoting muscle atrophy without other systemic effects (Madaro et al., 2018). Notably, in vivo pharmacological inhibition of IL-6 effectively counteracts denervation-mediated muscle atrophy (Madaro et al., 2018) and accumulation of FAPs with hyper-activation of IL-6 signaling has also been found in mouse models of amyotrophic lateral sclerosis (ALS) (Contreras et al., 2016; Madaro et al., 2018).

Taken together, these observations suggest two apparently opposing effects of FAPs-derived IL-6 during muscle regeneration or in denervation-induced muscle wasting, and further studies are needed to shed light on the molecular mechanisms behind these apparently contradictory roles.

\section{IL-33}

Interleukin-33 is a nuclear chromatin-associated cytokine, belonging to the IL-1 family, and constitutively expressed in the nucleus of a wide variety of cell types, including fibroblasts, epithelial cells, and endothelial cells (Carriere et al., 2007). IL-33 appears to function as an alarmin (alarm signal) that is rapidly released upon cellular damage and stress (Liew et al., 2016) and mediates a potent effect on the activation of regulatory $\mathrm{T}$ cell lymphocytes (Treg) (Matta et al., 2014; Alvarez et al., 2019).

In skeletal muscle, the major IL-33-producing cell type has been identified within the FAP cell population (Kuswanto et al., 2016). FAPs start to express IL-33 within $6-12 \mathrm{~h}$ after acute injury, inducing proliferation of muscle resident Treg (Kuswanto et al., 2016). As previously demonstrated, Treg cells promote muscle repair, accumulating in both acutely and chronically injured skeletal muscles (Burzyn et al., 2013; Castiglioni et al., 2015; Panduro et al., 2018). Interestingly, a severe decline in Treg accumulation, caused by an impairment in IL-33-producing FAPs, has been linked to regeneration defects in aged muscles (Kuswanto et al., 2016). On the other hand, in vivo treatment with IL-33 restored the Treg population in injured muscles of old mice, enhancing tissue regeneration.

Intriguingly, IL-33-expressing FAPs have been found in close association with muscle spindles (Kuswanto et al., 2016), which are stretch-sensitive mechanoreceptors that lie within the skeletal muscle and comprise both sensory and motor neurons. This finding raises the possibility that FAPs might function as mechano-cellular sensors that modulate the crosstalk between neural and immune cells to facilitate proper homeostatic reorganization of skeletal muscle and neural circuits upon injury. In agreement with this possibility, IL-33 expression is increased in fibroblasts upon mechanical stress (Kakkar et al., 2012) and PDGFR $\alpha^{+}$mesenchymal precursors, found within the endoneurium of peripheral nerves, have been recently implicated in tissue repair and regeneration (Carr et al., 2019).

\section{WISP1}

Wnt family member 1 (WNT1) inducible signaling pathway protein 1 (WISP1) is encoded by the cellular communication network factor 4 (CCN4) gene, a member of the CCN family of matricellular proteins that are involved in diverse biological processes, such as ECM remodeling, tissue repair, and tumor growth. CCN4/WISP1 is important in the musculoskeletal system, where it regulates osteogenesis and chondrogenesis, as well as skin repair (Ono et al., 2011, 2018; Maeda et al., 2015).

A recent study showed that in young mice CCN4/WISP1 is upregulated in FAPs following muscle injury, but this induction is lost in FAPs of old muscles (Lukjanenko et al., 2019). The FAP-secreted WISP1 plays an important role in SCs expansion and asymmetric commitment to myogenic differentiation. Indeed, similar to aging, the loss of WISP1 in knockout mice affects SCs function and impairs myogenesis. In agreement with this, the transplantation of young, but not aged or WISP $^{-/-}$FAPs, rescues the myogenic dysfunction of aged SCs and their regeneration ability (Lukjanenko et al., 2019). Even better, systemic treatment with recombinant WISP1 mimics rejuvenation beneficial effects, opening new prospects in the use of this approach as a strategy to counteract aging and associated muscular diseases.

Interestingly, these findings together with the reported impaired interplay between FAPs and Treg during aging (Kuswanto et al., 2016), the sensitivity of FAPs to muscle 

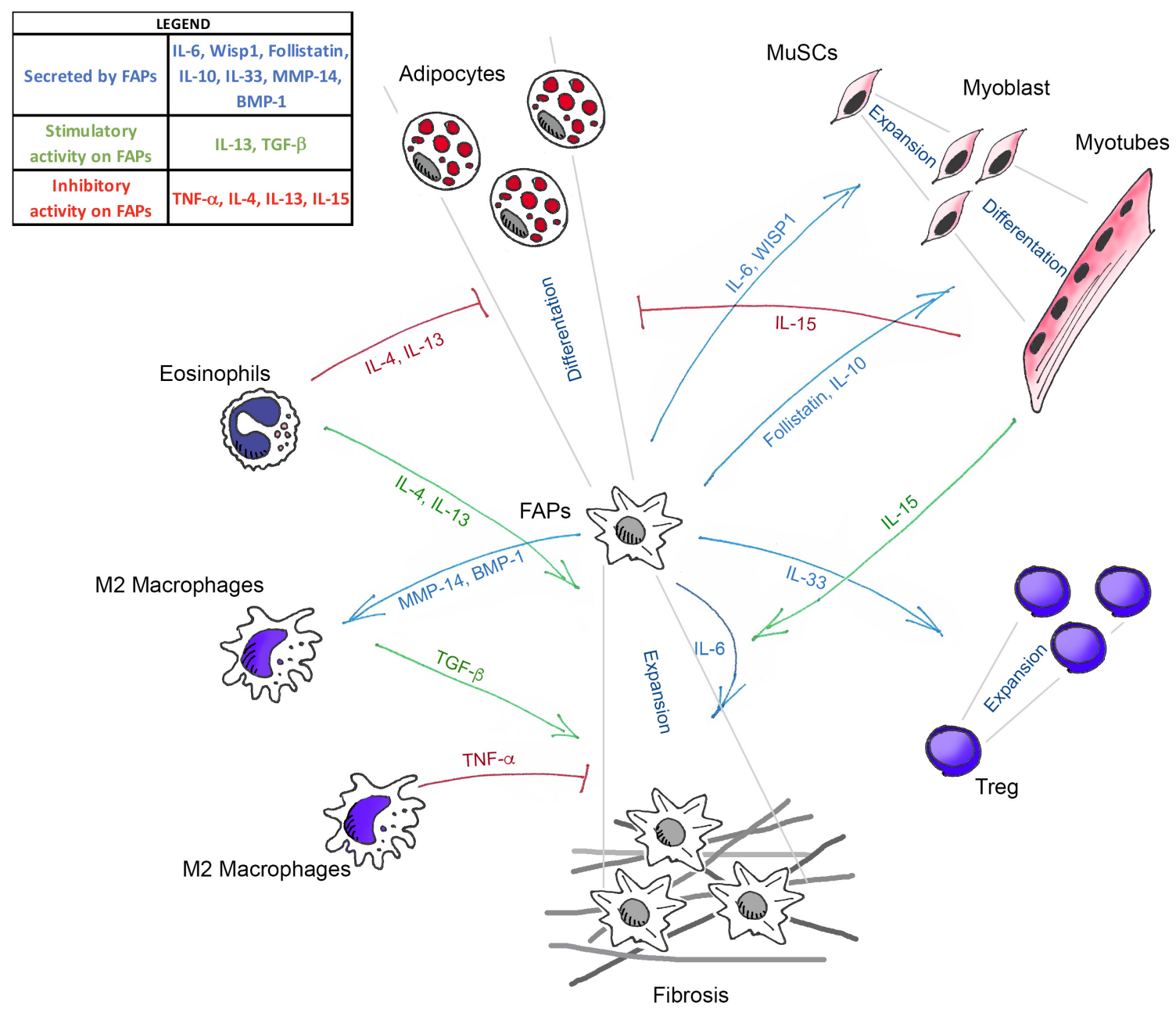

FIGURE 1 | Schematic illustration showing the known mediators that govern the interaction between FAPs, muscle stem cells (MuSCs), and the different immune cells in skeletal muscle homeostasis. Green arrows (TGF- $\beta$, IL-13, IL-4, and IL-15) indicate the molecules that positively regulate FAPs expansion. Blue arrows (IL-33, IL-6, Follistatin, IL-10, WISP1, MMP-14, and BMP-1) represent the molecules secreted by FAPs that act on the different cell targets. Red lines (TNF- $\alpha$, IL-4, IL-13, and IL-15) show the factors that inhibit the fibro-adipogenic differentiation of FAPs.

denervation (Madaro et al., 2018), and the recently reported atrophic phenotype of FAPs-depleted skeletal muscles (Wosczyna et al., 2019) clearly point toward FAPs as promising new cellular targets for the treatment of muscle defects associated with sarcopenia.

\section{Follistatin}

Follistatin is a potent natural antagonist of myostatin and activin A, two TGF- $\beta$ superfamily cytokines implicated in muscle growth inhibition, and it is therefore a potent pro-myogenic factor (Lee, 2007; Nakatani et al., 2008; Guo et al., 2009; Kota et al., 2009; Rodino-Klapac et al., 2009; Winbanks et al., 2012).

In the context of skeletal muscle regeneration, follistatin expression is induced $12 \mathrm{~h}$ after muscle injury (Iezzi et al., 2004) and remains elevated for 5 days, concurrent with SCs activation. Of note, FAPs have been described as the major source of follistatin, displaying 10-fold higher expression levels than SCs (Mozzetta et al., 2013; Formicola et al.,
2019). Follistatin is considered the central mediator of the fusogenic effects exerted by histone deacetylase inhibitors (HDACi) on skeletal muscles (Iezzi et al., 2004; Minetti et al., 2006; Mozzetta et al., 2013). Indeed, HDACi treatment in dystrophic mice induces the upregulation of follistatin in muscle progenitor cells, promoting the formation of multinucleated myotubes. In agreement with its promyogenic activity, follistatin knock-down in FAPs reduced the ability of HDACi to stimulate SCs-mediated formation of myotubes, suggesting a crucial role of FAP-derived follistatin as a mediator of the pro-differentiative activity of FAPs (Mozzetta et al., 2013).

A proper balance between follistatin and its antagonists is crucial to preserve reciprocal functional interactions between FAPs and SCs and to preserve muscle homeostasis (Baccam et al., 2019; Formicola et al., 2019). Indeed, pharmacological inhibition of the activin receptor type-2B pathway (AcvR2B), which blocks both myostatin and activin A activity, reverses muscle 
atrophy in SC-depleted skeletal muscles, while also restoring stem cells regenerative potential (Formicola et al., 2019). Of note, beneficial effects of AcvR2B targeting in SCs-depleted muscles are accompanied by an increased number of FAPs (Formicola et al., 2019), an observation that further supports the notion that restoration of a proper balance of regulatory factors between the different cells within the regenerative niche is key for muscle repair.

Once again, a role of FAPs emerges not only in regulating muscle regeneration but also in mediating signaling pathways associated with maintaining muscle mass. Future experiments should elucidate the possible use of FAPs as a source of trophic factors.

\section{IL-10}

Interleukin is a broadly expressed anti-inflammatory cytokine that inhibits the activation of the innate immune system and Th1 activation, preventing inflammatory and autoimmune pathologies (Saraiva and O'Garra, 2010; Ouyang et al., 2011). Like IL-6, IL-10 is also considered a myokine expressed in skeletal muscle in a wide range of conditions. It influences different aspects of muscle biology, such as regeneration, exercise, metabolism, and aging (Furmanczyk and Quinn, 2003; Nunes et al., 2008; Villalta et al., 2011; Deng et al., 2012; Dagdeviren et al., 2016, 2017). Its anti-inflammatory activity has been investigated in different muscle-related disorders (Hong et al., 2009; NitaharaKasahara et al., 2014; Villalta et al., 2014; Dagdeviren et al., 2016, 2017; Zhang et al., 2018). The main source of IL-10 in regenerating skeletal muscle is macrophages and Tregs (Villalta et al., 2011, 2014; Deng et al., 2012) although it has also been demonstrated that FAPs increase IL-10 expression upon muscle damage (Lemos et al., 2012). This evidence is in line with the crucial pro-myogenic activity of FAPs, which likely contribute to muscle repair also through the secretion of an anti-inflammatory cytokine, such as IL-10, to counteract the anti-myogenic activity of TNF- $\alpha$. Although the function of IL-10 released by FAPs has not yet been demonstrated in vivo, this work underscores the complexity of the interplay between inflammatory cells and the

\section{REFERENCES}

Allen, J. E., and Wynn, T. A. (2011). Evolution of Th2 immunity: a rapid repair response to tissue destructive pathogens. PLoS Pathog. 7:e1002003. doi: 10.1371/ journal.ppat.1002003

Alvarez, F., Istomine, R., Shourian, M., Pavey, N., Al-Aubodah, T. A.-F., Qureshi, S., et al. (2019). The alarmins IL-1 and IL-33 differentially regulate the functional specialisation of Foxp3+ regulatory $\mathrm{T}$ cells during mucosal inflammation. Mucosal Immunol. 12, 746-760. doi: 10.1038/s41385-0190153-5

Baccam, A., Benoni-Sviercovich, A., Rocchi, M., Moresi, V., Seelaender, M., Li, Z., et al. (2019). The mechanical stimulation of myotubes counteracts the effects of tumor-derived factors through the modulation of the activin/follistatin ratio. Front. Physiol. 24:401. doi: 10.3389/fphys.2019.00401

Baghdadi, M. B., Castel, D., Machado, L., Fukada, S., Birk, D. E., Relaix, F., et al. (2018). Reciprocal signalling by notch-collagen V-CALCR retains muscle stem cells in their niche. Nature 557, 714-718. doi: 10.1038/s41586-018-0144-149

Biernacka, A., Dobaczewski, M., and Frangogiannis, N. G. (2011). TGF- $\beta$ signaling in fibrosis. Growth Factors 29, 196-202. doi: 10.3109/08977194.2011.595714 other players in muscle regeneration. Future studies are needed to better understand this mechanism.

\section{CONCLUDING REMARKS}

In conclusion, the available evidence reviewed above clearly indicates that FAPs act as crucial regulators of skeletal muscle homeostasis (Figure 1). However, several critical issues need to be addressed before defining them as the co-star of skeletal muscle repair. First, their molecular heterogeneity makes it difficult to target them genetically, to uniquely assess their requirement, and to define the function of FAP-specific expression of the different factors described above. Future single-cell transcriptomic approaches will help identify subpopulations differently altered during the diverse stages of muscle regeneration and, more importantly, in pathological situations.

Finally, the evidence of the association of FAPs with nerve structures (Kuswanto et al., 2016), and the ability of FAPs to respond to nerve lesions (Contreras et al., 2016; Madaro et al., 2018), suggest a mechano-sensitivity of FAPs and emphasize the urgency to improve our understanding of the molecular regulation governing FAPs activity during muscle adaptation.

\section{AUTHOR CONTRIBUTIONS}

LM and CM wrote and edited the manuscript. BB and DP wrote the manuscript.

\section{FUNDING}

This work was supported by the Italian Ministry of Health (Grant No. GR-2013-02356592) to LM. CM was supported by a grant from the Italian Ministry of University and Research (SIR, Scientific Independence of Young Researcher no. RBSI14QMG0) and by a My First grant from the Italian Association for Cancer Research (AIRC), no. 18993.

Biressi, S., Miyabara, E. H., Gopinath, S. D., Carlig, P. M. M., and Rando, T. A. (2014). A Wnt-TGF $\beta 2$ axis induces a fibrogenic program in muscle stem cells from dystrophic mice. Sci. Transl. Med. 6:267ra176. doi: 10.1126/scitranslmed. 3008411

Buras, E. D., Converso-Baran, K., Davis, C. S., Akama, T., Hikage, F., Michele, D. E., et al. (2019). Fibro-adipogenic remodeling of the diaphragm in obesityassociated respiratory dysfunction. Diabetes 68, 45-56. doi: 10.2337/db180209

Burzyn, D., Kuswanto, W., Kolodin, D., Shadrach, J. L., Cerletti, M., Jang, Y., et al. (2013). A special population of regulatory T cells potentiates muscle repair. Cell 155, 1282-1295. doi: 10.1016/j.cell.2013.10.054

Busquets, S., Figueras, M. T., Meijsing, S., Carbó, N., Quinn, L. S., Almendro, V., et al. (2005). Interleukin-15 decreases proteolysis in skeletal muscle: a direct effect. Int. J. Mol. Med. 16, 471-476.

Carlson, M. E., Hsu, M., and Conboy, I. M. (2008). Imbalance between pSmad3 and Notch induces CDK inhibitors in old muscle stem cells. Nature 454, 528-532. doi: $10.1038 /$ nature 07034

Carr, M. J., Toma, J. S., Johnston, A. P. W., Steadman, P. E., Yuzwa, S. A., Mahmud, N., et al. (2019). Mesenchymal precursor cells in adult nerves contribute to 
mammalian tissue repair and regeneration. Cell Stem Cell 24, 240-256.e9. doi: 10.1016/j.stem.2018.10.024

Carriere, V., Roussel, L., Ortega, N., Lacorre, D.-A., Americh, L., Aguilar, L., et al. (2007). IL-33, the IL-1-like cytokine ligand for ST2 receptor, is a chromatinassociated nuclear factor in vivo. Proc. Natl. Acad. Sci. U.S.A. 104, 282-287. doi: 10.1073/pnas.0606854104

Castiglioni, A., Corna, G., Rigamonti, E., Basso, V., Vezzoli, M., Monno, A., et al. (2015). FOXP3 + T cells recruited to sites of sterile skeletal muscle injury regulate the fate of satellite cells and guide effective tissue regeneration. PLoS One 10:e0128094. doi: 10.1371/journal.pone.0128094

Chen, S.-E., Jin, B., and Li, Y.-P. (2007). TNF- $\alpha$ regulates myogenesis and muscle regeneration by activating p38 MAPK. Am. J. Physiol. Physiol. 292, C1660-C1671. doi: 10.1152/ajpcell.00486.2006

Contreras, O., Rebolledo, D. L., Oyarzún, J. E., Olguín, H. C., and Brandan, E. (2016). Connective tissue cells expressing fibro/adipogenic progenitor markers increase under chronic damage: relevance in fibroblast-myofibroblast differentiation and skeletal muscle fibrosis. Cell Tissue Res. 364, 647-660. doi: 10.1007/s00441-015-2343-0

Dagdeviren, S., Jung, D. Y., Friedline, R. H., Noh, H. L., Kim, J. H., Patel, P. R., et al. (2017). IL-10 prevents aging-associated inflammation and insulin resistance in skeletal muscle. FASEB J. 31, 701-710. doi: 10.1096/fj.201600832R

Dagdeviren, S., Jung, D. Y., Lee, E., Friedline, R. H., Noh, H. L., Kim, J. H., et al. (2016). Altered interleukin-10 signaling in skeletal muscle regulates obesitymediated inflammation and insulin resistance. Mol. Cell. Biol. 36, 2956-2966. doi: 10.1128/MCB.00181-116

Dammone, G., Karaz, S., Lukjanenko, L., Winkler, C., Sizzano, F., Jacot, G., et al. (2018). PPAR $\gamma$ controls ectopic adipogenesis and cross-talks with myogenesis during skeletal muscle regeneration. Int. J. Mol. Sci. 19:E2044. doi: 10.3390/ ijms 19072044

Davies, M. R., Liu, X., Lee, L., Laron, D., Ning, A. Y., Kim, H. T., et al. (2016). TGF- $\beta$ small molecule inhibitor SB431542 reduces rotator cuff muscle fibrosis and fatty infiltration by promoting fibro/adipogenic progenitor apoptosis. PLoS One 11:e0155486. doi: 10.1371/journal.pone.0155486

Deng, B., Wehling-Henricks, M., Villalta, S. A., Wang, Y., and Tidball, J. G. (2012). IL-10 triggers changes in macrophage phenotype that promote muscle growth and regeneration. J. Immunol. 189, 3669-3680. doi: 10.4049/jimmunol.110 3180

Dong, Y., Silva, K. A. S., Dong, Y., and Zhang, L. (2014). Glucocorticoids increase adipocytes in muscle by affecting IL-4 regulated FAP activity. FASEB J. 28, 4123-4132. doi: 10.1096/fj.14-254011

Ermolova, N. V., Martinez, L., Vetrone, S. A., Jordan, M. C., Roos, K. P., Sweeney, H. L., et al. (2014). Long-term administration of the TNF blocking drug remicade $(\mathrm{cVlq})$ to $\mathrm{mdx}$ mice reduces skeletal and cardiac muscle fibrosis, but negatively impacts cardiac function. Neuromuscul. Disord. 24, 583-595. doi: 10.1016/j.nmd.2014.04.006

Feige, P., Brun, C. E., Ritso, M., and Rudnicki, M. A. (2018). Orienting muscle stem cells for regeneration in homeostasis. Aging Dis. Cell Stem Cell 23, 653-664. doi: $10.1016 /$ j.stem.2018.10.006

Fiore, D., Judson, R. N., Low, M., Lee, S., Zhang, E., Hopkins, C., et al. (2016). Pharmacological blockage of fibro/adipogenic progenitor expansion and suppression of regenerative fibrogenesis is associated with impaired skeletal muscle regeneration. Stem Cell Res. 17, 161-169. doi: 10.1016/j.scr.2016. 06.007

Formicola, L., Pannérec, A., Correra, R. M., Gayraud-Morel, B., Ollitrault, D., Besson, V., et al. (2019). Inhibition of the activin receptor type-2B pathway restores regenerative capacity in satellite cell-depleted skeletal muscle. Front. Physiol. 9:515. doi: 10.3389/fphys.2018.00515

Fry, C. S., Johnson, D. L., Ireland, M. L., and Noehren, B. (2017a). ACL injury reduces satellite cell abundance and promotes fibrogenic cell expansion within skeletal muscle. J. Orthop. Res. 35, 1876-1885. doi: 10.1002/jor.23502

Fry, C. S., Kirby, T. J., Kosmac, K., McCarthy, J. J., and Peterson, C. A. (2017b). Myogenic progenitor cells control extracellular matrix production by fibroblasts during skeletal muscle hypertrophy. Cell Stem Cell 20, 56-69. doi: 10.1016/j. stem.2016.09.010

Furmanczyk, P. S., and Quinn, L. S. (2003). Interleukin-15 increases myosin accretion in human skeletal myogenic cultures. Cell Biol. Int. 27, 845-851. doi: 10.1016/s1065-6995(03)00172-0
Giordani, L., He, G. J., Negroni, E., Sakai, H., Law, J. Y. C., Siu, M. M., et al. (2019). High-dimensional single-cell cartography reveals novel skeletal muscleresident cell populations. Mol. Cell. 74, 609-621.e6. doi: 10.1016/j.molcel.2019. 02.026

González, M. N., de Mello, W., Butler-Browne, G. S., Silva-Barbosa, S. D., Mouly, V., Savino, W., et al. (2017). HGF potentiates extracellular matrix-driven migration of human myoblasts: involvement of matrix metalloproteinases and MAPK/ERK pathway. Skelet. Muscle 7:20. doi: 10.1186/s13395-017-0138-6

Gorski, T., Mathes, S., and Krützfeldt, J. (2018). Uncoupling protein 1 expression in adipocytes derived from skeletal muscle fibro/adipogenic progenitors is under genetic and hormonal control. J. Cachexia. Sarcopenia Muscle 9, 384-399. doi: 10.1002/jcsm. 12277

Guo, T., Jou, W., Chanturiya, T., Portas, J., Gavrilova, O., and McPherron, A. C. (2009). Myostatin inhibition in muscle, but not adipose tissue, decreases fat mass and improves insulin sensitivity. PLoS One 4:e4937. doi: 10.1371/journal. pone.0004937

Haddad, F., Zaldivar, F., Cooper, D. M., and Adams, G. R. (2005). IL-6-induced skeletal muscle atrophy. J. Appl. Physiol. 98, 911-917. doi: 10.1152/japplphysiol. 01026.2004

Heredia, J. E., Mukundan, L., Chen, F. M., Mueller, A. A., Deo, R. C., Locksley, R. M., et al. (2013). Type 2 innate signals stimulate fibro/adipogenic progenitors to facilitate muscle regeneration. Cell 153, 376-388. doi: 10.1016/j.cell.2013.02. 053

Hodgetts, S., Radley, H., Davies, M., and Grounds, M. D. (2006). Reduced necrosis of dystrophic muscle by depletion of host neutrophils, or blocking TNF $\alpha$ function with etanercept in mdx mice. Neuromuscul. Disord. 16, 591-602. doi: 10.1016/j.nmd.2006.06.011

Hong, E.-G., Ko, H. J., Cho, Y.-R., Kim, H.-J., Ma, Z., Yu, T. Y., et al. (2009). Interleukin-10 prevents diet-induced insulin resistance by attenuating macrophage and cytokine response in skeletal muscle. Diabetes 58, 2525-2535. doi: $10.2337 / \mathrm{db} 08-1261$

Huang, P., Zhao, X. S., Fields, M., Ransohoff, R. M., and Zhou, L. (2009). Imatinib attenuates skeletal muscle dystrophy in mdx mice. FASEB J. 23, 2539-2548. doi: 10.1096/fj.09-129833

Iezzi, S., Di Padova, M., Serra, C., Caretti, G., Simone, C., Maklan, E., et al. (2004). Deacetylase inhibitors increase muscle cell size by promoting myoblast recruitment and fusion through induction of follistatin. Dev. Cell 6, 673-684. doi: 10.1016/s1534-5807(04)00107-8

Joe, A. W. B., Yi, L., Natarajan, A., Le Grand, F., So, L., Wang, J., et al. (2010). Muscle injury activates resident fibro/adipogenic progenitors that facilitate myogenesis. Nat. Cell Biol. 12, 153-163. doi: 10.1038/ncb2015

Juban, G., Saclier, M., Yacoub-Youssef, H., Kernou, A., Arnold, L., Boisson, C., et al. (2018). AMPK activation regulates LTBP4-dependent TGF- $\beta 1$ secretion by pro-inflammatory macrophages and controls fibrosis in duchenne muscular dystrophy. Cell Rep. 25, 2163-2176.e6. doi: 10.1016/j.celrep.2018.10.077

Judson, R. N., Low, M., Eisner, C., and Rossi, F. M. (2017). Isolation, culture, and differentiation of fibro/adipogenic progenitors (FAPs) from skeletal muscle. Methods Mol. Biol. 1668, 93-103. doi: 10.1007/978-1-4939-72 83-8-7

Kakkar, R., Hei, H., Dobner, S., and Lee, R. T. (2012). Interleukin 33 as a mechanically responsive cytokine secreted by living cells. J. Biol. Chem. 287, 6941-6948. doi: 10.1074/jbc.M111.298703

Kang, X., Yang, M., Shi, Y., Xie, M., Zhu, M., Zheng, X., et al. (2018). Interleukin15 facilitates muscle regeneration through modulation of fibro/adipogenic progenitors. Cell Commun. Signal. 16:42. doi: 10.1186/s12964-0180251-0

Kopinke, D., Roberson, E. C., and Reiter, J. F. (2017). Ciliary hedgehog signaling restricts injury-induced adipogenesis. Cell 170, 340-351.e12. doi: 10.1016/j.cell. 2017.06.035

Kota, J., Handy, C. R., Haidet, A. M., Montgomery, C. L., Eagle, A., RodinoKlapac, L. R., et al. (2009). Follistatin Gene Delivery enhances muscle growth and strength in nonhuman primates. Sci. Transl. Med. 1:6ra15. doi: 10.1126/ scitranslmed.3000112

Kuswanto, W., Burzyn, D., Panduro, M., Wang, K. K., Jang, Y. C., Wagers, A. J., et al. (2016). Poor repair of skeletal muscle in aging mice reflects a defect in local, interleukin-33-dependent accumulation of regulatory T cells. Immunity 44, 355-367. doi: 10.1016/j.immuni.2016.01.009 
Lee, S.-J. (2007). Quadrupling muscle mass in mice by targeting TGF- $\beta$ signaling pathways. PLoS One 2:e789. doi: 10.1371/journal.pone.0000789

Lees-Shepard, J. B., Yamamoto, M., Biswas, A. A., Stoessel, S. J., Nicholas, S.-A. E., Cogswell, C. A., et al. (2018). Activin-dependent signaling in fibro/adipogenic progenitors causes fibrodysplasia ossificans progressiva. Nat. Commun. 9:471. doi: 10.1038/s41467-018-02872-2

Lemos, D. R., Babaeijandaghi, F., Low, M., Chang, C.-K., Lee, S. T., Fiore, D., et al. (2015). Nilotinib reduces muscle fibrosis in chronic muscle injury by promoting TNF-mediated apoptosis of fibro/adipogenic progenitors. Nat. Med. 21, 786-794. doi: 10.1038/nm.3869

Lemos, D. R., Paylor, B., Chang, C., Sampaio, A., Underhill, T. M., and Rossi, F. M. V. (2012). Functionally convergent white adipogenic progenitors of different lineages participate in a diffused system supporting tissue regeneration. Stem Cells 30, 1152-1162. doi: 10.1002/stem.1082

Liew, F. Y., Girard, J.-P., and Turnquist, H. R. (2016). Interleukin-33 in health and disease. Nat. Rev. Immunol. 16, 676-689. doi: 10.1038/nri.2016.95

Lukjanenko, L., Karaz, S., Stuelsatz, P., Gurriaran-Rodriguez, U., Michaud, J., Dammone, G., et al. (2019). Aging disrupts muscle stem cell function by impairing matricellular WISP1 secretion from fibro-adipogenic progenitors. Cell Stem Cell 24, 433-446.e7. doi: 10.1016/j.stem.2018.12.014

Madaro, L., Passafaro, M., Sala, D., Etxaniz, U., Lugarini, F., Proietti, D., et al. (2018). Denervation-activated STAT3-IL-6 signalling in fibro-adipogenic progenitors promotes myofibres atrophy and fibrosis. Nat. Cell Biol. 20, 917927. doi: 10.1038/s41556-018-0151-y

Maeda, A., Ono, M., Holmbeck, K., Li, L., Kilts, T. M., Kram, V., et al. (2015). WNT1-induced secreted protein-1 (WISP1), a novel regulator of bone turnover and wnt signaling. J. Biol. Chem. 290, 14004-14018. doi: 10.1074/jbc.M114. 628818

Malecova, B., Gatto, S., Etxaniz, U., Passafaro, M., Cortez, A., Nicoletti, C., et al. (2018). Dynamics of cellular states of fibro-adipogenic progenitors during myogenesis and muscular dystrophy. Nat. Commun. 9:3670. doi: 10.1038/ s41467-018-06068-6

Matta, B. M., Lott, J. M., Mathews, L. R., Liu, Q., Rosborough, B. R., Blazar, B. R., et al. (2014). IL-33 is an unconventional alarmin that stimulates IL-2 secretion by dendritic cells to selectively expand IL-33R/ST2 + regulatory T cells. J. Immunol. 193, 4010-4020. doi: 10.4049/jimmunol.1400481

Meng, X., Nikolic-Paterson, D. J., and Lan, H. Y. (2016). TGF- $\beta$ : the master regulator of fibrosis. Nat. Rev. Nephrol. 12, 325-338. doi: 10.1038/nrneph. 2016.48

Minetti, G. C., Colussi, C., Adami, R., Serra, C., Mozzetta, C., Parente, V., et al. (2006). Functional and morphological recovery of dystrophic muscles in mice treated with deacetylase inhibitors. Nat. Med. 12, 1147-1150. doi: 10.1038/ nm1479

Moratal, C., Raffort, J., Arrighi, N., Rekima, S., Schaub, S., Dechesne, C. A., et al. (2018). IL-1 $\beta$ - and IL-4-polarized macrophages have opposite effects on adipogenesis of intramuscular fibro-adipogenic progenitors in humans. Sci. Rep. 8:17005. doi: 10.1038/s41598-018-35429-w

Mozzetta, C., Consalvi, S., Saccone, V., Tierney, M., Diamantini, A., Mitchell, K. J., et al. (2013). Fibroadipogenic progenitors mediate the ability of HDAC inhibitors to promote regeneration in dystrophic muscles of young, but not old Mdx mice. EMBO Mol. Med. 5, 626-639. doi: 10.1002/emmm.20120 2096

Mueller, A. A., van Velthoven, C. T., Fukumoto, K. D., Cheung, T. H., and Rando, T. A. (2016). Intronic polyadenylation of PDGFR $\alpha$ in resident stem cells attenuates muscle fibrosis. Nature 540, 276-279. doi: 10.1038/nature20160

Muñoz-Cánoves, P., Scheele, C., Pedersen, B. K., and Serrano, A. L. (2013). Interleukin-6 myokine signaling in skeletal muscle: a double-edged sword. FEBS J. 280, 4131-4148. doi: 10.1111/febs.12338

Murphy, M. M., Lawson, J. A., Mathew, S. J., Hutcheson, D. A., and Kardon, G. (2011). Satellite cells, connective tissue fibroblasts and their interactions are crucial for muscle regeneration. Development 138, 3625-3637. doi: 10.1242/dev. 064162

Nakatani, M., Takehara, Y., Sugino, H., Matsumoto, M., Hashimoto, O., Hasegawa, Y., et al. (2008). Transgenic expression of a myostatin inhibitor derived from follistatin increases skeletal muscle mass and ameliorates dystrophic pathology in mdx mice. FASEB J. 22, 477-487. doi: 10.1096/fj.07-8673com

Nitahara-Kasahara, Y., Hayashita-Kinoh, H., Chiyo, T., Nishiyama, A., Okada, H., Takeda, S., et al. (2014). Dystrophic mdx mice develop severe cardiac and respiratory dysfunction following genetic ablation of the anti-inflammatory cytokine IL-10. Hum. Mol. Genet. 23, 3990-4000. doi: 10.1093/hmg/ ddu113

Nunes, R. B., Tonetto, M., Machado, N., Chazan, M., Heck, T. G., Veiga, A. B. G., et al. (2008). Physical exercise improves plasmatic levels of IL-10, left ventricular end-diastolic pressure, and muscle lipid peroxidation in chronic heart failure rats. J. Appl. Physiol. 104, 1641-1647. doi: 10.1152/japplphysiol.00062. 2008

Ono, M., Inkson, C. A., Kilts, T. M., and Young, M. F. (2011). WISP-1/CCN4 regulates osteogenesis by enhancing BMP-2 activity. J. Bone Miner. Res. 26, 193-208. doi: 10.1002/jbmr.205

Ono, M., Masaki, A., Maeda, A., Kilts, T. M., Hara, E. S., Komori, T., et al. (2018), CCN4/WISP1 controls cutaneous wound healing by modulating proliferation, migration and ECM expression in dermal fibroblasts via $\alpha 5 \beta 1$ and TNF $\alpha$. Matrix Biol. 6, 533-546. doi: 10.1016/j.matbio.2018.01.004

Ouyang, W., Rutz, S., Crellin, N. K., Valdez, P. A., and Hymowitz, S. G. (2011). Regulation and functions of the IL-10 family of cytokines in inflammation and disease. Annu. Rev. Immunol. 29, 71-109. doi: 10.1146/annurev-immunol031210-101312

Pagano, A. F., Brioche, T., Arc-Chagnaud, C., Demangel, R., Chopard, A., and Py, G. (2018). Short-term disuse promotes fatty acid infiltration into skeletal muscle. J. Cachexia. Sarcopenia Muscle 9, 335-347. doi: 10.1002/JCSM.12259

Palacios, D., Mozzetta, C., Consalvi, S., Caretti, G., Saccone, V., Proserpio, V., et al. (2010). TNF/p38 $\alpha /$ Polycomb signaling to Pax7 locus in satellite cells links inflammation to the epigenetic control of muscle regeneration. Cell Stem Cell 7, 455-469. doi: 10.1016/j.stem.2010.08.013

Palm, N. W., Rosenstein, R. K., and Medzhitov, R. (2012). Allergic host defences. Nature 484, 465-472. doi: 10.1038/nature11047

Panduro, M., Benoist, C., and Mathis, D. (2018). T reg cells limit IFN- $\gamma$ production to control macrophage accrual and phenotype during skeletal muscle regeneration. Proc. Natl. Acad. Sci. U.S.A. 115, E2585-E2593. doi: 10. 1073/pnas. 1800618115

Pannérec, A., Marazzi, G., and Sassoon, D. (2012). Stem cells in the hood: the skeletal muscle niche. Trends Mol. Med. 18, 599-606. doi: 10.1016/j.molmed. 2012.07.004

Pedersen, B. K., and Febbraio, M. A. (2008). Muscle as an endocrine organ: focus on muscle-derived interleukin-6. Physiol. Rev. 88, 1379-1406. doi: 10.1152/ physrev.90100.2007

Pedersen, B. K., Steensberg, A., Keller, P., Keller, C., Fischer, C., Hiscock, N., et al. (2003). Muscle-derived interleukin-6: lipolytic, anti-inflammatory and immune regulatory effects. Pflügers Arch. Eur. J. Physiol. 446, 9-16. doi: 10.1007/s00424002-0981-z

Piers, A. T., Lavin, T., Radley-Crabb, H. G., Bakker, A. J., Grounds, M. D., and Pinniger, G. J. (2011). Blockade of TNF in vivo using cV1q antibody reduces contractile dysfunction of skeletal muscle in response to eccentric exercise in dystrophic mdx and normal mice. Neuromuscul. Disord. 21, 132-141. doi: 10.1016/j.nmd.2010.09.013

Quinn, L., Straitbodey, L., Anderson, B., Argiles, J., and Havel, P. (2005). Interleukin-15 stimulates adiponectin secretion by 3T3-L1 adipocytes: evidence for a skeletal muscle-to-fat signaling pathway. Cell Biol. Int. 29, 449-457. doi: 10.1016/j.cellbi.2005.02.005

Quinn, L. S., Anderson, B. G., Drivdahl, R. H., Alvarez, B., and Argilés, J. M. (2002). Overexpression of interleukin-15 induces skeletal muscle hypertrophy in vitro: implications for treatment of muscle wasting disorders. Exp. Cell Res. 280, 55-63. doi: 10.1006/excr.2002.5624

Rebolledo, D. L., González, D., Faundez-Contreras, J., Contreras, O., Vio, C. P., Murphy-Ullrich, J. E., et al. (2019). Denervation-induced skeletal muscle fibrosis is mediated by CTGF/CCN2 independently of TGF- $\beta$. Matrix Biol. doi: 10.1016/j.matbio.2019.01.002 [Epub ahead of print].

Rodino-Klapac, L. R., Haidet, A. M., Kota, J., Handy, C., Kaspar, B. K., and Mendell, J. R. (2009). Inhibition of myostatin with emphasis on follistatin as a therapy for muscle disease. Muscle Nerve 39, 283-296. doi: 10.1002/mus.21244

Saccone, V., Consalvi, S., Giordani, L., Mozzetta, C., Barozzi, I., Sandona, M., et al. (2014). HDAC-regulated myomiRs control BAF60 variant exchange and direct the functional phenotype of fibro-adipogenic progenitors in dystrophic muscles. Genes Dev. 28, 841-857. doi: 10.1101/gad.234468.113

Saraiva, M., and O'Garra, A. (2010). The regulation of IL-10 production by immune cells. Nat. Rev. Immunol. 10, 170-181. doi: 10.1038/nri2711 
Serrano, A. L., Baeza-Raja, B., Perdiguero, E., Jardí, M., and Muñoz-Cánoves, P. (2008). Interleukin-6 is an essential regulator of satellite cell-mediated skeletal muscle hypertrophy. Cell Metab. 7, 33-44. doi: 10.1016/j.cmet.2007. 11.011

Serrano, A. L., and Muñoz-Cánoves, P. (2010). Regulation and dysregulation of fibrosis in skeletal muscle. Exp. Cell Res. 316, 3050-3058. doi: 10.1016/J.YEXCR. 2010.05.035

Song, Y., Yao, S., Liu, Y., Long, L., Yang, H., Li, Q., et al. (2017). Expression levels of TGF- $\beta 1$ and CTGF are associated with the severity of duchenne muscular dystrophy. Exp. Ther. Med. 13, 1209-1214. doi: 10.3892/etm.2017. 4105

Tatsumi, R., Sankoda, Y., Anderson, J. E., Sato, Y., Mizunoya, W., Shimizu, N., et al. (2009). Possible implication of satellite cells in regenerative motoneuritogenesis: HGF upregulates neural chemorepellent Sema3A during myogenic differentiation. Am. J. Physiol. Cell Physiol. 297, C238-C252. doi: 10.1152/ajpcell.00161.2009

Tidball, J. G., and Villalta, S. A. (2010). Regulatory interactions between muscle and the immune system during muscle regeneration. Am. J. Physiol. Integr. Comp. Physiol. 298, R1173-R1187. doi: 10.1152/ajpregu.00735.2009

Tierney, M. T., Aydogdu, T., Sala, D., Malecova, B., Gatto, S., Puri, P. L., et al. (2014). STAT3 signaling controls satellite cell expansion and skeletal muscle repair. Nat. Med. 20, 1182-1186. doi: 10.1038/nm.3656

Travis, M. A., and Sheppard, D. (2014). TGF- $\beta$ activation and function in immunity. Annu. Rev. Immunol. 32, 51-82. doi: 10.1146/annurev-immunol032713-120257

Uezumi, A., Fukada, S., Yamamoto, N., Takeda, S., and Tsuchida, K. (2010). Mesenchymal progenitors distinct from satellite cells contribute to ectopic fat cell formation in skeletal muscle. Nat. Cell Biol. 12, 143-152. doi: 10.1038/ ncb2014

Uezumi, A., Ito, T., Morikawa, D., Shimizu, N., Yoneda, T., Segawa, M., et al. (2011). Fibrosis and adipogenesis originate from a common mesenchymal progenitor in skeletal muscle. J. Cell Sci. 124, 3654-3664. doi: 10.1242/jcs. 086629

Verma, M., Asakura, Y., Murakonda, B. S. R., Pengo, T., Latroche, C., Chazaud, B., et al. (2018). Muscle satellite cell cross-talk with a vascular niche maintains quiescence via VEGF and notch signaling. Cell Stem Cell 23, 530-543.e9. doi: 10.1016/j.stem.2018.09.007

Villalta, S. A., Rinaldi, C., Deng, B., Liu, G., Fedor, B., and Tidball, J. G. (2011). Interleukin-10 reduces the pathology of $\mathrm{mdx}$ muscular dystrophy by deactivating M1 macrophages and modulating macrophage phenotype. Hum. Mol. Genet. 20, 790-805. doi: 10.1093/hmg/ddq523
Villalta, S. A., Rosenthal, W., Martinez, L., Kaur, A., Sparwasser, T., Tidball, J. G., et al. (2014). Regulatory T cells suppress muscle inflammation and injury in muscular dystrophy. Sci. Transl. Med. 6:258ra142. doi: 10.1126/scitranslmed. 3009925

Wang, X., Shen, Q. W., Wang, J., Zhang, Z., Feng, F., Chen, T., et al. (2016). KLF7 regulates satellite cell quiescence in response to extracellular signaling. Stem Cells 34, 1310-1320. doi: 10.1002/stem.2346

Warren, G. L., Hulderman, T., Mishra, D., Gao, X., Millecchia, L., O'Farrell, L., et al. (2005). Chemokine receptor CCR2 involvement in skeletal muscle regeneration. FASEB J. 19, 413-415. doi: 10.1096/fj.04-2421fje

Winbanks, C. E., Weeks, K. L., Thomson, R. E., Sepulveda, P. V., Beyer, C., Qian, H., et al. (2012). Follistatin-mediated skeletal muscle hypertrophy is regulated by Smad3 and mTOR independently of myostatin. J. Cell Biol. 197, 997-1008. doi: $10.1083 /$ jcb.201109091

Wosczyna, M. N., Konishi, C. T., Perez Carbajal, E. E., Wang, T. T., Walsh, R. A., Gan, Q., et al. (2019). Mesenchymal stromal cells are required for regeneration and homeostatic maintenance of skeletal muscle. Cell Rep. 27, 2029-2035.e5. doi: 10.1016/j.celrep.2019.04.074

Wosczyna, M. N., and Rando, T. A. (2018). A muscle stem cell support group: coordinated cellular responses in muscle regeneration. Dev. Cell. 46, 135-143. doi: 10.1016/j.devcel.2018.06.018

Zhang, C., Qiao, Y., Huang, L., Li, F., Zhang, Z., Ping, Y., et al. (2018). Regulatory T cells were recruited by CCL3 to promote cryo-injured muscle repair. Immunol. Lett. 204, 29-37. doi: 10.1016/j.imlet.2018.10.004

Zhang, P., He, J., Wang, F., Gong, J., Wang, L., Wu, Q., et al. (2019). Hemojuvelin is a novel suppressor for duchenne muscular dystrophy and age-related muscle wasting. J. Cachexia. Sarcopenia Muscle 10, 557-573. doi: 10.1002/jcsm.12414

Conflict of Interest Statement: The authors declare that the research was conducted in the absence of any commercial or financial relationships that could be construed as a potential conflict of interest.

The handling Editor declared a shared affiliation, though no other collaboration, with several of the authors, $\mathrm{BB}, \mathrm{CM}$, and DP, at the time of review.

Copyright (c) 2019 Biferali, Proietti, Mozzetta and Madaro. This is an open-access article distributed under the terms of the Creative Commons Attribution License (CC BY). The use, distribution or reproduction in other forums is permitted, provided the original author(s) and the copyright owner(s) are credited and that the original publication in this journal is cited, in accordance with accepted academic practice. No use, distribution or reproduction is permitted which does not comply with these terms. 